\title{
Detection of Copper (II) and Iron (III) in Aqueous Solutions Using the Spectroscopic Characteristics of Bugnay (Antidesma bunius) Anthocyanins
}

\author{
Jonathan M. Barcelo, Jan Narlo Abril' ${ }^{1}$, Khristine Mereille P. \\ Castillo ${ }^{1}$, Alloisa Diaz ${ }^{1}$, Jonathan Paul Ladera ${ }^{1}$, Jaemie Javar ${ }^{1}$ \\ and Elisha Labuguen ${ }^{2}$
}

\begin{abstract}
${ }^{1}$ Saint Louis University, Bonifacio Street, Baguio City, Philippines 2600, ${ }^{2}$ Student Researcher, School of Natural Sciences Saint Louis University Bonifacio Street, Baguio City, Philippines 2600
\end{abstract}

\section{ABSTRACT}

The spectrophotometric characteristics of bugnay (Antidesma bunius) anthocyanins in acidified solutions of copper $\left(\mathrm{Cu}^{2+}\right)$ and iron $\left(\mathrm{Fe}^{3+}\right)$ were investigated after one hour of reaction to determine the changes in their absorbance characteristics. Anthocyanins from bugnay were isolated using solid phase extraction followed by evaporation at $40^{\circ} \mathrm{C}$. The total anthocyanin content of the extract was determined to be $103.87 \pm 2.91 \mathrm{mg} / \mathrm{L}$ cyanidin-30 -glucoside equivalents using $\mathrm{pH}$ differential method. Maximum absorbance readings at $\mathrm{pH} 1.0$ and 4.5 were determined to be at $520 \mathrm{~nm}$ and $350 \mathrm{~nm}$, respectively. Cyanidin-3-glucoside was identified as one of the components of the three pigments in the extract using reversed phase high performance liquid chromatography. At $\mathrm{pH}$ 1.0, copper caused greater hypochromic shift of bugnai anthocyanins compared to iron $(\rho<0.01)$ while iron caused greater hypochromic shift at $\mathrm{pH}$ 4.5. Copper also caused hypsochromic shift of anthocyanins from $520 \mathrm{~nm}$ to $350 \mathrm{~nm}$ at $\mathrm{pH} 1.0$ but not at $\mathrm{pH}$ 4.5. Correlation analysis showed a significant moderate positive correlation between mean \% hypochromic shift and concentration of copper ions at $\mathrm{pH} 1.0\left(R^{2}=0.603\right.$, $\rho<0.01)$ and $4.5\left(R^{2}=0.533, \rho<0.01\right)$, and iron at $\mathrm{pH} 4.5\left(R^{2}=0.638, \rho<0.01\right)$. The spectroscopic characteristics of bugnay anthocyanins at $350 \mathrm{~nm}$ and 520 nm can be used as parameters to detect copper and iron in acidic solutions.

Keywords: Anthocyanins, Antidesma bunius, cyanidin-3-0-glucoside, hypochromic shift hypsochromic shift 


\section{INTRODUCTION}

Anthocyanins are universal food colorants which give the red, purple, and blue hues in fruits, vegetables, cereal grains, and flowers (Konczak and Zhang, 2004). Brouillard et al. (2010) stated that the basic structure common to almost all anthocyanins is a chromophoric 2phenylbenzopyrylium (flavylium) heterocyclic skeleton bearing at least one sugar residue. At present, anthocyanins are being studied for their antioxidant activities. According to Rein (2005), anthocyanins are highly unstable and are easily affected by $\mathrm{pH}$, solvents, temperature, oxygen, light, enzymes, and other accompanying substances. Anthocyanins can also undergo copigmentation with several compounds.

Anthocyanins which are based from cyanidin, delphinidin and petunidin were previously reported to form metal complexes with aluminum (Moncada et al., 2003), copper (Sarma et al., 1997), iron and tin (Pyysalo and Kuusi, 1973). Cheng and Crisosto (1997) reported that ferric ions $\left(\mathrm{Fe}^{3+}\right)$ showed high affinity to cyanidin-3-glucoside, caffeic acid, chlorogenic acid, catechin and epicatechin. However, these studies did not elaborate the changes in the properties of anthocyanins after forming complexes with metals. The formation of metal-anthocyanin complexes of cyanidin, delphinidin and petunidin with the abovementioned metals was attributed to the orthodihydroxyl arrangement or 3', 4'-o-diphenolic groups in the B ring of the compound (Brouillard et al., 2010).

The tropical fruit bugnay (Antidesma bunius), a member of family Euphorbiaceae, has been reported to contain anthocyanins and is accounted for the red coloration of the seed coat (Amelia et al., 2006). It is also called buni or berunai in Malaya, wooni or hooni in Indonesia, ma mao luang in Thailand, kho lien tu in Laos, choi moi in Vietnam, and moi-kin and chunka by the aborigines in Queensland. Among its English names are Chinese laurel, currant tree, nigger's cord, and salamander tree (Morton, 1987).

Copper and iron are beneficial elements in the body, but excessive levels are dangerous. They cannot be destroyed in the environment and may accumulate in the body resulting to liver damage and acute poisoning (Ozer and Tumen, 2005). Excess iron can cause other metals such as copper, calcium, and manganese to accumulate in the body by binding with them, and they become deposited in the wrong places and cause harm (Lavie, 1998). Since the only possible ways to remove excess iron and copper in the body are phlebotomy and metal chelation, preventing iron and copper toxicity is preferred by detecting the concentration of metals in water and food products. 
Copper and iron have been reported to be involved in the oxidative browning of anthocyanin-rich wines (Li et al., 2008). Natural blue pigments were reported by Pyysalo and Kuusi (1973) to be formed when anthocyanins having two hydroxyl groups in ortho position bind with divalent metals. It is expected that anthocyanins which are based from cyanidin, delphinidin, and petunidin will decolorize when they are mixed with divalent metals.

Sarma et al. (1997) hypothesized that divalent copper ions can also form complexes with cyanidin-based anthocyanins although no other descriptions were discussed. Changes in the property of anthocyanins in the presence of copper and iron may serve as parameters for their quantification using anthocyanins.

With these concerns, this study investigated the spectroscopic changes in bugnay anthocyanins in the presence of iron and copper in acidic aqueous solutions. The spectroscopic changes were evaluated for their potential to serve as parameters for detecting metals in acidic aqueous solutions. Specifically, the study aimed to compare the absorbance of bugnay anthocyanins in terms of color and spectroscopic characteristics at pH 1.0 and 4.5, compare its spectroscopic characteristics in acidic solutions of iron and copper at $\mathrm{pH} 1.0$ and 4.5, and determine the relationship of its observed spectroscopic shift with the concentrations of iron and copper. The results of the study can be used as a possible alternative method in detecting copper and iron in aqueous solutions.

\section{MATERIALS AND METHODS}

\section{Plant Material}

Bugnay fruits, which were obtained from La Trinidad, Benguet, were brought to the Saint Louis University Natural Science Research Unit (SLUNSRU), oven dried for $24 \mathrm{~h}$ at $100^{\circ} \mathrm{C}$, and powdered coarsely. The powdered plant sample was immersed in $85 \%$ methanol with $0.1 \% \mathrm{HCl}$ for $72 \mathrm{~h}$ according to the methodology of Jenshiroobha et al. (2011). The methanolic extract was filtered twice using Whatman No.1 filter paper and stored in the refrigerator at $4^{\circ} \mathrm{C}$.

\section{Apparatus}

High performance liquid chromatography was performed using Shimadzu Degasser DG2-12A, Shimadzu Diode Array Detector SPD-M10A, 
and Shimadzu Fraction Collector FRC 10A. Solid phase extraction (SPE) columns packed with reversed phase octadecylsilane $\left(\mathrm{C}_{18}\right)$ bonded to silica gel with $40 \mu \mathrm{m}$ APD, $60 \AA$ (Bakerbond $\mathrm{spe}^{\mathrm{TM}}$ ) were used to isolate anthocyanins from the fruit samples. The SPE columns were attached to Supelco Visiprep ${ }^{\mathrm{TM}}$ DL at $30 \mathrm{mmHg}$ vacuum pressure. A Visspectrophotometer (PD 303) was used in determining the absorbance of bugnay anthocyanins at various concentrations of copper and iron.

\section{Chemicals and Solutions}

Cyanidin-3-0-glucoside chloride ( $>98.29 \%$, HPLC grade) or $2-(3$, 4 - D i hydroxy p he nyl) - 3 - ( $\beta$ - D - g l u c opyran o s y oxy ) 5,7-dihydroxy-1-benzopyrylium chloride was purchased from Chemleader Biomedical Corporation Limited (Shanghai, China). Methanol (HPLC Grade, RCl Labscan Limited) ethyl acetate (Fisher Scientific), potassium chloride (Fisher Scientific), sodium acetate trihydrate (RCl Labscan), ferric chloride (Fisher Scientific), and nitric acid (Fisher Scientific) were obtained from SLU-NSRU. All reagents used were of analytical grade.

\section{Isolation of bugnay anthocyanins using solid phase extraction}

The methanolic extracts were placed in a flask and evaporated at $40^{\circ} \mathrm{C}$ using a rotatory evaporator. The methodology of Qin et al. (2010) was modified to isolate anthocyanins from the methanolic extracts. Briefly, the aqueous extracts were loaded to Solid Phase Extraction (SPE) Columns (Bakerbond spe ${ }^{\mathrm{TM}}$ Octadecylsilane, $500 \mathrm{mg}$ sorbent) which were previously activated with methanol and acidified distilled water $(0.1 \% \mathrm{HCl}$ in distilled water). Anthocyanins which were absorbed by the column were eluted with acidified distilled water $(0.1 \% \mathrm{HCl}$ distilled water $)$ and ethyl acetate to remove sugar and polyphenolic compounds, respectively. The procedure was performed thrice to saturate the $500 \mathrm{mg}$ sorbent with anthocyanins. Anthocyanins were eluted twice using acidified methanol.

\section{Determination of Total Anthocyanin Content}

Total anthocyanin content was determined using $\mathrm{pH}$ differential method (AOAC Official Method, 2006). Two buffer solutions (pH 1.0 and 4.5) were prepared for determining the absorbance of anthocyanins. The pH 1.0 buffer solution was prepared by dissolving $1.86 \mathrm{~g} \mathrm{KCl}$ in $1000 \mathrm{~mL}$ distilled water. The $\mathrm{pH}$ of the solution was adjusted to 1.0 using 
concentrated $\mathrm{HCl}$. The $\mathrm{pH} 4.5$ buffer solution was prepared by dissolving $54.43 \mathrm{~g} \mathrm{CH}_{3} \mathrm{COONa} \cdot 3 \mathrm{H}_{2} \mathrm{O}$ in $1000 \mathrm{~mL}$ distilled water. The $\mathrm{pH}$ was also adjusted to 4.5 using concentrated $\mathrm{HCl}$. In a clean test tube, $1 \mathrm{~mL}$ of anthocyanin extract was added to $10 \mathrm{~mL}$ of $\mathrm{pH} 1.0$ buffer solution. The same procedure was done to buffer solution $\mathrm{pH}$ 4.5. The buffer solutions were used as blank to adjust the absorbance of the diluted anthocyanin extracts. Spectrophotometric readings were measured at $520 \mathrm{~nm}$ and 700 $\mathrm{nm}$ according to the following equation:

$$
\begin{aligned}
& \mathrm{A}=\left(A_{520}-A_{700}\right)_{p H 1.0}-\left(A_{520}-A_{700}\right)_{p H 4.5} \\
& \operatorname{TAC}(\mathbf{m g} / \mathbf{L})=\frac{\mathbf{A} \times \mathbf{M W} \times \mathbf{D F} \times 1000}{\varepsilon \times \mathbf{~ l}}
\end{aligned}
$$

The unit for total anthocyanin content was expressed as mg/L cyanidin-3-glucoside equivalents (Cyd-3-glu eq, MW of cyanidin-3-0glucoside $\left.=449.2 \mathrm{~g}^{*} \mathrm{~mol}^{-1,} \varepsilon=26,900 \mathrm{~L}^{*} \mathrm{~cm}^{-1 *} \mathrm{~mol}^{-1}, \mathrm{DF}=10, \mathrm{l}=1 \mathrm{~cm}\right)$.

\section{Preparation of copper and iron standard solutions}

The methodology of Ozer and Tumen (2005) was utilized in the study. The stock solution of copper was prepared by dissolving 1 gram of copper wire with nitric acid solution to remove oxide films, air dried, and dissolved in $5 \mathrm{ml}$ of concentrated nitric acid in a $1000 \mathrm{ml}$ flask. Distilled water was added up to the mark. The stock solution of iron was prepared by dissolving $4.33 \mathrm{~g}$ of $\mathrm{Fe}\left(\mathrm{NO}_{3}\right)$ to $1 \mathrm{~L}$ distilled water. The metal solutions were diluted as required to obtain working solutions of copper and iron. A solution composed of copper and iron was also prepared to compare the spectroscopic shifts with solutions of copper and iron. The solution $\mathrm{pH}$ was adjusted to the required value by using $0.1 \mathrm{M} \mathrm{NaOH}$ and $0.1 \mathrm{M}^{\mathrm{HNO}_{3}}$ solution.

Determination of spectra of bugnay anthocyanins in copper and iron solutions

The visible spectra of anthocyanins from $340 \mathrm{~nm}$ to $800 \mathrm{~nm}$ at $\mathrm{pH} 1.0$ and 4.5 were determined spectrophotometrically using a quartz cuvette at increments of $10 \mathrm{~nm}$. The peak wavelengths and linearity of spectroscopic shifts were recorded and utilized to determine the characteristics of bugnay anthocyanins in copper and iron solutions. The spectra of 
anthocyanins were compared to a corresponding blank sample at each concentration.

\section{Partial identification of anthocyanin in bugnay anthocyanin extract}

In a $50 \mathrm{~mL}$ amber volumetric flask, $5 \mathrm{mg}$ of cyanidin-3-0-glucoside chloride was dissolved in $80 \%$ methanol to produce a $100 \mu \mathrm{g} / \mathrm{mL}$ standard solution. The extraction of anthocyanins from bugnay using solid phase extraction was modified by using acidified $80 \%$ methanol as the final eluent to anthocyanins adsorbed in the sorbent. The mobile phase used in the study was $80 \%$ methanol (HPLC grade). The standard solution was filtered using a Whatman filter paper $(0.45 \mu \mathrm{m}$ pore size $)$ attached to a $5 \mathrm{~mL}$ syringe before loading to the HPLC apparatus.

A volume of $25 \mu \mathrm{L}$ of the filtered standard solution was loaded to the column (Inertsil ODS-3V, $5 \mu \mathrm{M}, 2.1 \times 250 \mathrm{~mm}$ ) at a flow rate of 0.5 $\mathrm{mL} /$ minute. Isocratic elution was performed at $23^{\circ} \mathrm{C}$ for $10 \mathrm{~min}$. The chromatogram of bugnay anthocyanins was compared to an authentic cyanidin-3-0-glucoside chloride at $254 \mathrm{~nm}, 280 \mathrm{~nm}, 340 \mathrm{~nm}$ and $520 \mathrm{~nm}$. The UV-vis spectrum of cyanidin-3-0-glucoside was compared to the UVvis spectrum of bugnay anthocyanins to determine the identity of the unknown compound in the extract.

\section{Determination of\% hypochromic shift}

Since the study hypothesized that the addition of metals to anthocyanins can cause a decrease in the absorbance (hypochromic shift) of bugnay anthocyanins, \% hypochromic shift was determined using the formula:

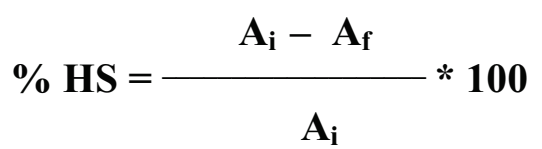

Where: $\quad A_{i}=$ initial absorbance

$\mathrm{A}_{\mathrm{f}}=$ final absorbance

\section{Treatment of Data}

The comparison of change of absorbance in different treatments was analyzed using One Way Analysis of Variance at $\alpha=0.01$. A post hoc Tukey's HSD test was utilized to determine where the significant difference lies 
among the different treatments. Data on correlating the UV-Vis spectra of the standard and isolated bugnay anthocyanin was computed using Pearson Product-Moment Coefficient of Correlation at $\alpha=0.01$ (two tailed). Data on spectroscopic changes of bugnay anthocyanins at various concentrations of iron and copper ions in $\mathrm{pH} 1.0$ and 4.5 buffers were presented in graphs and tables. Data for changes in mean \% absorbance differences were presented as mean \pm SD. Statistical evaluation was performed using SPSS 18.0 for Windows at $\alpha=0.01$.

\section{RESULTS AND DISCUSSION}

\section{Total anthocyanin content}

Using the $\mathrm{pH}$ differential method, the average total anthocyanin content of bugnay anthocyanin was $103.87 \pm 2.91 \mathrm{mg} / \mathrm{L}$ cyanidin-3-0glucoside equivalents $(n=7)$ or $6.87 \mathrm{mg} / \mathrm{g}$ dry weight of bugnay. The percentage yield in the study using acidified $85 \%$ methanol was higher than the result obtained by Amelia et al., (2006) using $1 \% \mathrm{HCl}$ in distilled water, $3 \%$ citric acid in distilled water, $3 \%$ citric acid in $70 \%$ ethanol and $1 \% \mathrm{HCl}$ in $70 \%$ ethanol. The difference in the result can be explained by the method of extraction used and the soaking time of bugnay fruits. This study used powdered bugnay fruits and three-day soaking time while the study of Amelia et al. (2006) utilized mashed fresh fruits after one-day soaking time.

\section{Spectroscopic characteristics of bugnay anthocyanin}

At $\mathrm{pH}$ 1.0, the isolated bugnay anthocyanins appeared bright red while the color changed to faint purple at $\mathrm{pH}$ 4.5. The visible spectrum shown in Figure 1 revealed that at $\mathrm{pH} 1.0$, maximum absorbance $\left(\lambda_{\max }\right)$ was at $520 \mathrm{~nm}$, although another peak was noted at $350 \mathrm{~nm}$. At pH $4.5, \lambda_{\max }$ was noted at $350 \mathrm{~nm}$ while hypochromic shift was observed at $520 \mathrm{~nm}$. The results are similar to the spectrum reported by Wrolstad et al. (2005).

Brouillard et al. (2010) discussed that in strongly acidic aqueous solutions, anthocyanins are in their orange or red flavylium cation form which is highly stable (Figure 2). The positive charge is delocalized through all the pyrilium moieties, but carbons 2 and 4 are more positively charged. The deprotonation of $\mathrm{OH}$ groups at 4' and 7 causes color changes. At $\mathrm{pH} 4$, one of the $\mathrm{OH}$ group loses a proton producing a quinoid base. 
At $\mathrm{pH}$ levels close to neutral, a second deprotonation occurs forming the purplish, anionic quinoidal base. Quinoidal bases cause color changes which are detected at longer wavelengths. In addition, the flavylium cation is also susceptible to nucleophilic attack. At a pH level greater than two, water molecules cause the loss of color of the flavylium cation, forming a hemiketal, also known as carbinol pseudobase. This could further progress to ring opening forming retrochalcones.

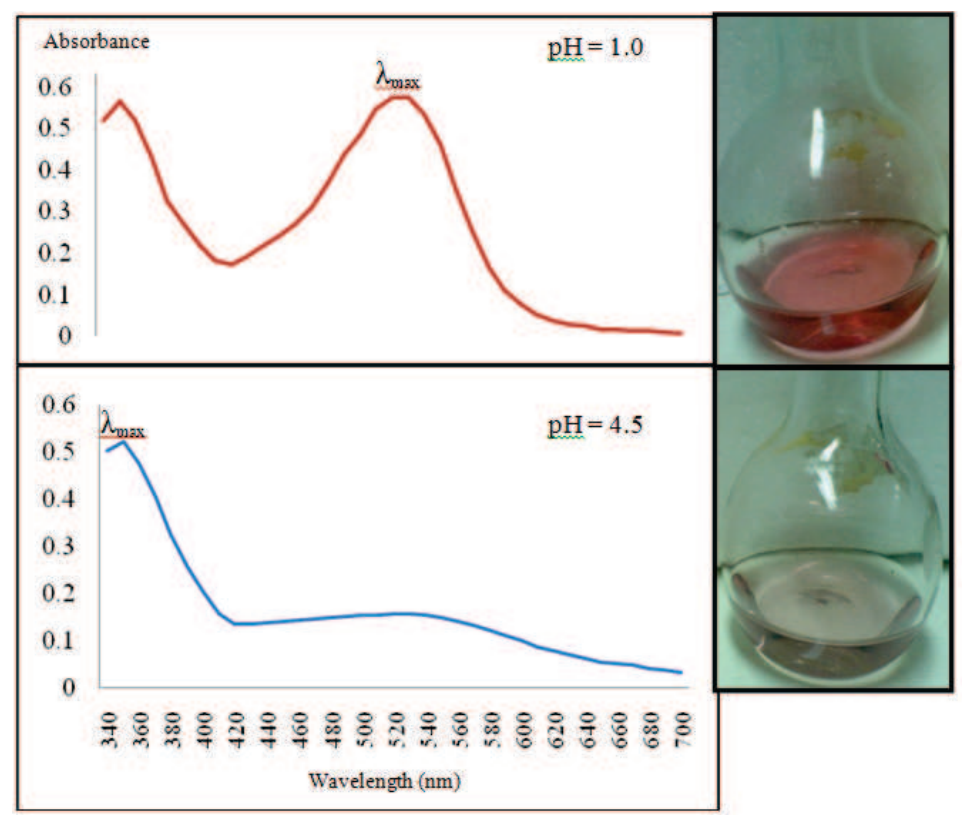

Figure 1: Mean Visible Spectra of Bugnay Anthocyanin at pH 1.0 and 4.5 (Inset: Appearance of bugnay anthocyanin solution at pH 1.0 and 4.5)<smiles></smiles>

Figure 2. General Structure of Flavylium Cation 


\section{Composition of bugnay anthocyanins}

The UV-vis spectra of one of the bugnay anthocyanins and cyanidin-30 -glucoside are shown in Figure 3. The spectra of the bugnay anthocyanin and the standard were derived from isocratic HPLC at a retention time of $6.73 \mathrm{~min}$ and $6.87 \mathrm{~min}$, respectively. Based on the results of high performance liquid chromatography, the identity of the peak in the bugnay anthocyanin at 6.73 was similar to the spectrum of the cyanidin-3-0glucoside chloride $(R=0.933, \mathrm{p}<0.01)$. The results suggest that bugnay anthocyanin may contain a cyanidin-3-0-glucoside-like compound.

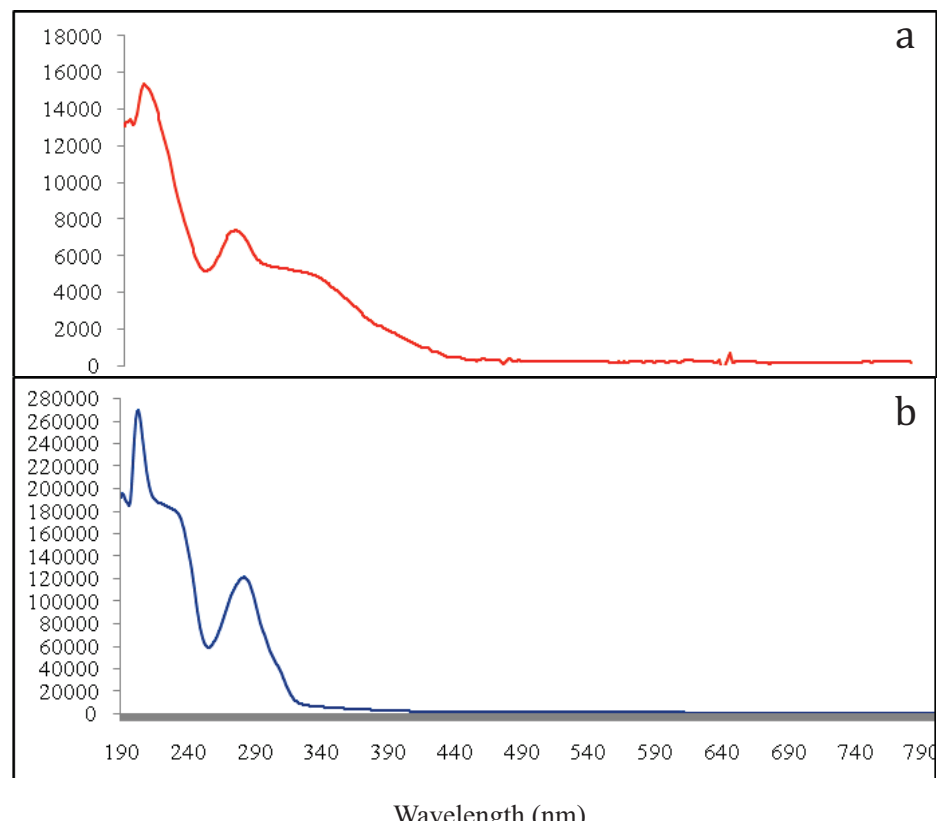

Figure 3: UV-Vis-spectrum of isolated bugnay anthocyanin (a) and cyanindin-3-O-glucoside chloride (b).

The HPLC chromatograms of bugnay anthocyanin and cyanidin-3-0glucoside chloride at $254 \mathrm{~nm}, 280 \mathrm{~nm}$, and $340 \mathrm{~nm}$ (not shown) revealed definite peaks and minimized noise while significant amount of noise and tailing was noted at $520 \mathrm{~nm}$. Three peaks were revealed in bugnay anthocyanins at $4.8 \mathrm{~min}, 6.73 \mathrm{~min}$ and $8.45 \mathrm{~min}$ at $254 \mathrm{~nm}, 280 \mathrm{~nm}, 340 \mathrm{~nm}$, and $520 \mathrm{~nm}$. The best appearance of peaks were shown at $254 \mathrm{~nm}$ and 340 $\mathrm{nm}$. 
Detection of copper and iron in aqueous solutions using spectroscopic

Spectrophotometric Characteristics of bugnay anthocyanins in copper and iron solutions at $\mathrm{pH} 1.0$ and 4.5

Figure 4 reveals that the copper and iron cause a decrease in the absorbance (hypochromic shift) of bugnay anthocyanins at pH 1 and 4.5. The hypochromic shift caused by copper is greater than that of iron in all concentrations at wavelengths $340 \mathrm{~nm}$ to $380 \mathrm{~nm}$ and $500 \mathrm{~nm}$ to $560 \mathrm{~nm}$ at $\mathrm{pH}$ 1.0. However, at pH 4.5, iron causes slightly greater hypochromic shift at wavelengths $340 \mathrm{~nm}$ to $380 \mathrm{~nm}$.

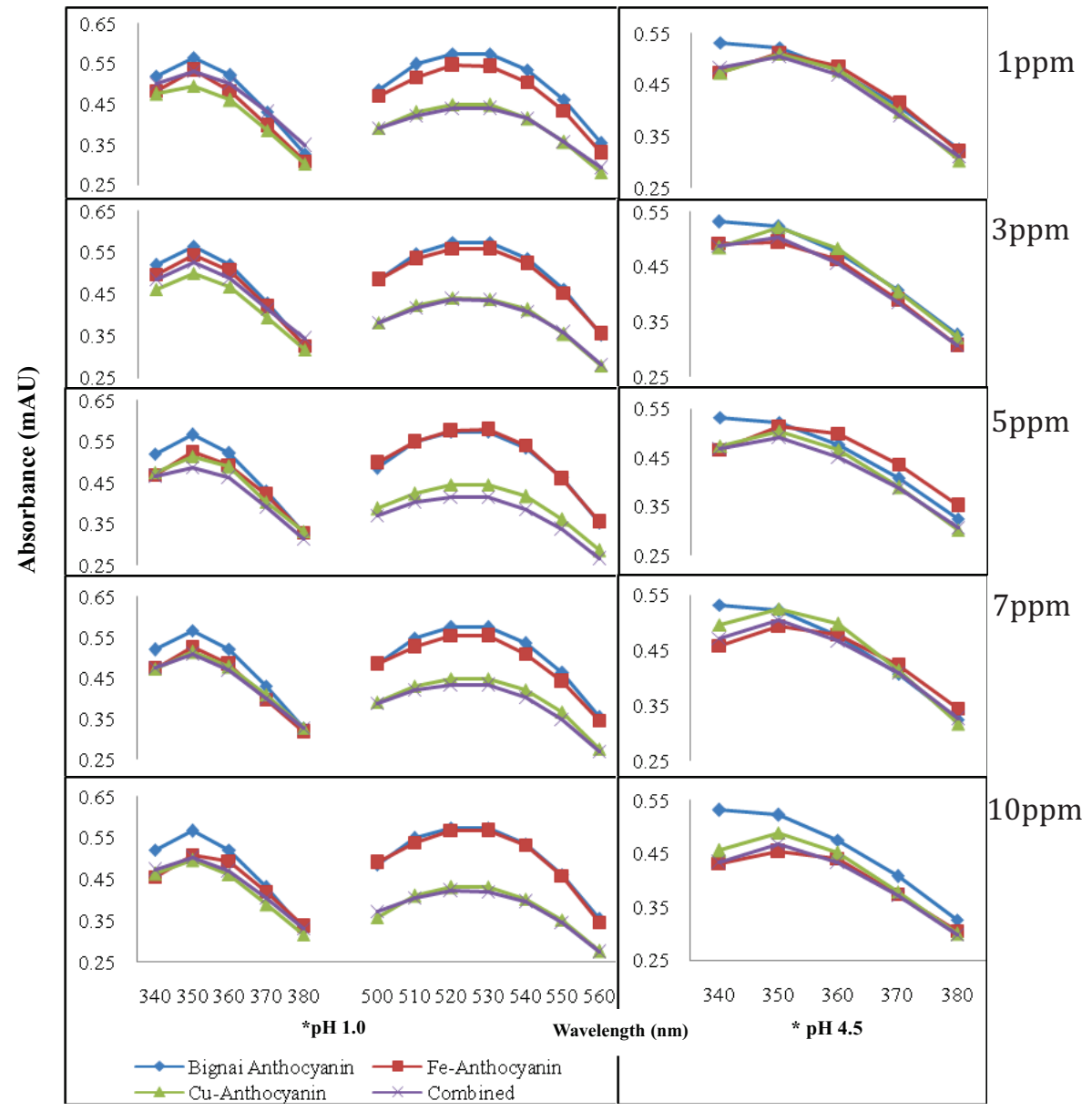

Figure 4: Mean Absorbance of Bugnay (Bignai) Anthocyanins in Various Concentrations of Copper and Iron at $\mathrm{pH} 1.0$ and 4.5 
The maximum absorbance of bugnay anthocyanins was noted at $520 \mathrm{~nm}$ and $350 \mathrm{~nm}$ in all copper and iron solutions at pH 1.0 and 4.5, respectively. Furthermore, the hypochromic shift of bugnay anthocyanins in copper solutions seems to have a striking similarity with the hypochromic shift in solutions containing both copper and iron. Aside from hypochromic shift, it was also noted that at $\mathrm{pH} 1.0$, maximum absorbance $\left(\lambda_{\max }\right)$ of bugnay anthocyanins changed from $520 \mathrm{~nm}$ to $350 \mathrm{~nm}$ (hypsochromic shift) in copper solution and copper-iron solution.

A change in the absorbance of anthocyanin implies the formation of a new compound through the copigmentation phenomenon (Rein, 2005) which could yield changes in absorbance such as hypsochromic shift (shift towards higher wavelengths), hypsochromic shift (shift towards shorter wavelengths), hyperchromic shift (increased absorbance), or hypochromic shift (decrease in absorbance). Furthermore, intermolecular interactions can occur with both the flavylium cation, quinoidal base forms and chalcones since these molecules are almost planar with efficiently delocalized pi electrons.

These pigments are able to form intermolecular interactions because they have the same structural features. Furthermore, the formation of hydrogen bonds between the keto group of the quinoidal base at $\mathrm{pH}>4.0$ and a copigment has been suggested as a possible means of complex formation.

The hypochromic effect of copper to bugnay anthocyanins at $\mathrm{pH} 1.0$ can be attributed to its strong oxidizing property of the metal. Sarma et al. (1999) reported that copper potentiates the oxidation of ascorbic acid, leading to hypochromic shift. The same mechanism could have caused the hypochromic shift in bugnay anthocyanins because anthocyanins are also potent antioxidants like ascorbic acid.

Comparison of mean \% hypochromic shift of bugnay anthocyanins in copper and iron solutions at $\mathrm{pH} 1.0$

Table 1 shows the mean \% hypochromic shift of bugnay anthocyanins in various solutions of copper and iron at $\mathrm{pH} 1.0(\mathrm{n}=5)$. The greatest mean $\%$ absorbance difference was caused by the solution which has both copper and iron. The least mean \% absorbance difference was observed in solutions containing iron. At $\alpha=0.01$, there was a significant difference between the different solutions as determined by one-way Analysis of Variance in $1 \mathrm{ppm}(F(2,14)=1035.091, \rho<0.01), 3 \mathrm{ppm}(F(2,14)=840.098$, 
$\rho<0.01), 5 p p m(F(2,14)=606.542, \rho<0.01), 7 \mathrm{ppm}(F(2,14)=3883.009, \rho$ $<0.00)$, and $10 \mathrm{ppm}(F(2,14)=949.697, \rho<0.01)$.

Table 1: Mean \% Hypochromicity Index of Metal-Anthocyanin Complexes at pH 1.0

\begin{tabular}{lccccc}
\hline & \multicolumn{4}{c}{ Metal Concentration } \\
\cline { 2 - 5 } & $1 \mathrm{ppm}$ & $3 \mathrm{ppm}$ & $5 \mathrm{ppm}$ & $7 \mathrm{ppm}$ & $10 \mathrm{ppm}$ \\
\hline $\begin{array}{l}\text { Copper-anthocyanin } \\
\text { complex }\end{array}$ & $22.73 \pm 0.93^{\mathrm{a}}$ & $21.68 \pm 0.64^{\mathrm{a}}$ & $21.82 \pm 0.74^{\mathrm{a}}$ & $22.38 \pm 0.61^{\mathrm{a}}$ & $25.00 \pm 0.53^{\mathrm{a}}$ \\
$\begin{array}{l}\text { Iron-anthocyanin } \\
\text { complex }\end{array}$ & $2.86 \pm 1.54^{\mathrm{b}}$ & $2.69 \pm 1.28^{\mathrm{b}}$ & $2.61 \pm 1.56^{\mathrm{b}}$ & $2.30 \pm 0.53^{\mathrm{b}}$ & $2.68 \pm 1.56^{\mathrm{b}}$ \\
& & & & \\
$\begin{array}{l}\text { Combined copper- and iron- } \\
\text { anthocyanin complexes }\end{array}$ & $23.81 \pm 0.95^{\mathrm{a}}$ & $23.22 \pm 0.53^{\mathrm{a}}$ & $24.37 \pm 0.72^{\mathrm{a}}$ & $27.75 \pm 0.21^{\mathrm{c}}$ & $26.60 \pm 0.23^{\mathrm{a}}$ \\
\hline
\end{tabular}

Values with different letters are significant at $\alpha=0.01, n=5, \lambda \max =520 \mathrm{~nm}$

A post hoc Tukey's HSD test revealed that in all concentrations of copper and iron, the copper significantly causes greater mean $\%$ absorbance difference compared to iron. Furthermore, there was no significant difference between the mean $\%$ absorbance caused by copper solutions and copper-iron solutions. This means that a hypochromic shift can be used as a parameter to detect copper in solutions which contains other metals if the $\mathrm{pH}$ of the solution is 1.0.

Metal complexation with anthocyanins was hypothesized to be hydrophobic in nature. George et al. (1999) reported that malvidin-ferric ion complex was stabilized by hydrogen bonds between the chromophore of the anthocyanin and a glycosyl residue, trapping the cation in between as revealed by proton nuclear magnetic resonance. Metal complexation has been supported with few literatures because of their little significance in the food industry. Several mechanisms were also explained by earlier studies. Moncada et al. (2003) stated that in vivo, metals seem to organize anthocyanins, exposing a polar outer layer (the sugars) and keeping hydrophobic centers in the center. The hydrophobic catechol group was explained to cause metal-anthocyanin complexation.

At $\mathrm{pH}$ 4.5, the quinoidal bases are anionic while chalcones are characterized by ring opening of the flavylium cation, losing its positive charge. The anionic characteristic of the quinoidal bases may form complexes with metals through the deprotonated hydroxyl groups in the catechol group of the benzopyrilium ring. Furthermore, a free cavity in chalcones seems to be formed allowing iron to form complexes with anthocyanins.

Based on the results of the study, it can be theorized then that the formation of metal-anthocyanin complexes may vary from one metal to 
another. Copper seems to oxidize the anthocyanin molecule especially at hydroxyl groups at carbons $3^{\prime}$ and 4 ' and promotes binding with the catechol group. However, the positive charge in the pyrilium ring might have caused repulsion with excess copper ions in the solution, preferring complex formation with anthocyanins at a ratio of 1:2.

The formation of copper-anthocyanin complex at $\mathrm{pH} 4.5$ using the proposed scheme may also explain the minimal hypochromicity of bugnay anthocyanins since the formation of metal-anthocyanin complex may have occurred at a 1:1 or even 1:2 ratio if other reducing agents such as ascorbic acid are available, thereby causing a shift in the absorbance of the whole complex.

Iron formed complexes with anthocyanins at $\mathrm{pH} 4.5$ with chalcones as proposed by George et al. (1999) using malvin-Z-chalcone. Since the anionic character of the anthocyanin increases at $\mathrm{pH}$ levels above 4.0, it is likely that 1:1 ratio of anthocyanin to a metal is harder to maintain since anthocyanins have deprotonated twice providing only two anionic sites ready for complexation with a cation. Iron $\left(\mathrm{Fe}^{3+}\right)$ cations need three anionic sites, thereby requiring another molecule of catechol-bearing anthocyanin. In chalcones, the free cavity might have promoted better complexation with iron because of several intermolecular hydrogen bonds. However, it should be noted that the same scheme could also be possible for copper, but the two anionic sites in the catechol ring of the anthocyanin would suffice to form a stable complex with divalent copper ions.

At $\mathrm{pH}$ 1.0, a lesser hypochromic shift might imply that metalanthocyanin complex cannot occur at a ratio of 1:1 for catechol bearing anthocyanins. Second, greater repulsion between the charged pyrilium ring and trivalent iron seems to be the cause why complex formation at $\mathrm{pH}$ 1.0 is minimal compared to complexation with copper, forcing multiple anthocyanin pigments to combine with iron.

Table 2 shows the mean \% absorbance difference of bugnay anthocyanins in various solutions of copper and iron at $\mathrm{pH} 4.5$. The greatest mean\% absorbance difference was observed in the solution which has iron. The least mean \% absorbance difference was observed in copper solutions. At $\alpha=0.01$, there was a significant difference between the different solutions as determined by one-way Analysis of Variance in $1 \mathrm{ppm}$ $(F(2,14)=17.438, \rho<0.01), 5 \mathrm{ppm}(F(2,14)=20.134, \rho<0.01), 7 \mathrm{ppm}$ $(F(2,14)=81.744, \rho<0.01)$, and $10 \operatorname{ppm}(F(2,14)=11.701, \rho<0.01)$. There were no significant differences in the mean $\%$ absorbance among the metal solutions at $3 \mathrm{ppm}((F(2,14)=1.903, \rho=0.191)$. 
Detection of copper and iron in aqueous solutions using spectroscopic

Table 2: Mean \% Hypochromicity Index of Metal-Anthocyanin Complexes at pH 4.5

\begin{tabular}{llllll}
\hline & \multicolumn{4}{c}{ Concentration } \\
\cline { 2 - 5 } & $1 \mathrm{ppm}$ & $3 \mathrm{ppm}$ & $5 \mathrm{ppm}$ & $7 \mathrm{ppm}$ & $10 \mathrm{ppm}$ \\
\hline $\begin{array}{l}\text { Copper-anthocyanin } \\
\text { Complex }\end{array}$ & $1.38 \pm 0.32^{\mathrm{a}}$ & $2.37 \pm 1.16^{\mathrm{a}}$ & $3.44 \pm 1.06^{\mathrm{a}}$ & $0.81 \pm 0.82^{\mathrm{a}}$ & $6.32 \pm 0.87^{\mathrm{a}}$ \\
$\begin{array}{l}\text { Iron-anthocyanin } \\
\text { Complex }\end{array}$ & $5.43 \pm 1.50^{\mathrm{b}}$ & $1.91 \pm 1.02^{\mathrm{a}}$ & $1.53 \pm 1.27^{\mathrm{a}}$ & $5.21 \pm 0.24^{\mathrm{b}}$ & $13.10 \pm 3.72^{\mathrm{b}}$ \\
$\begin{array}{l}\text { Combined copper- and iron- } \\
\text { anthocyanin complexes }\end{array}$ & $3.52 \pm 1.28^{\mathrm{b}}$ & $3.21 \pm 1.03^{\mathrm{a}}$ & $6.12 \pm 1.11^{\mathrm{b}}$ & $3.25 \pm 0.99^{\mathrm{c}}$ & $10.40 \pm 0.62^{\mathrm{a}}$ \\
\hline
\end{tabular}

*Values with different letters are significant at $\alpha=0.01, \mathrm{n}=5, \lambda_{\max }=350 \mathrm{~nm}$

Based from the summary of the absorbance shifts at pH 1.0 and 4.5, correlation analysis was performed. Table 3 shows that the maximum absorbance was observed at $520 \mathrm{~nm}$ and $350 \mathrm{~nm}$ at $\mathrm{pH} 1.0$ and 4.5, respectively. There was a significant moderate positive correlation $(\rho<0.01)$ between the mean $\%$ absorbance difference (hypochromic shift) of bugnay anthocyanin and concentration of metals in $\mathrm{pH} 1.0$ and 4.5. Iron also showed significant moderate positive correlation between mean \% absorbance difference and concentration at $\mathrm{pH} 4.5$ but not at $\mathrm{pH}$ 1.0.

Table 3: Summary of Correlation Coefficients of Metal-Anthocyanin Complexes at pH 1.0 and 4.5 .

\begin{tabular}{lccc}
\hline Metal-anthocyanin Complex & $\mathrm{pH}$ & $\lambda_{\max }$ & $R^{2} *$ \\
\hline & & & \\
Copper-anthocyanin complex & 1.0 & 520 & $0.603^{* *}$ \\
& 4.5 & 350 & $0.533^{* *}$ \\
Bugnay anthocyanin with iron & 1.0 & 520 & 0.335 \\
& 4.5 & 350 & $0.638^{* *}$ \\
\hline
\end{tabular}

* Correlation between mean hypochromicity index and metal concentration

**Correlation is significant at $\alpha=0.01$ (2-tailed)

Several methods have been reported by other studies in detecting copper and iron in solutions and food samples. These methods include spectrophotometric determination using morin (Ahmed \& Roy, 2009), reductimetric titration (Patrudu \& Raju, 2011), electrothermal and flame atomic absorption spectroscopy (Acar et al., 2005). Compared to atomic absorption spectroscopy and titration methods, utilizing spectrophotometry with chromogens such as morin and anthocyanin is cheaper and easier to perform, making the detection and quantification of metals possible in small laboratory setting. The simplicity of the spectrophotometric method also requires less preparation time and 
technical instrumentation skills, making it a good choice for rapid estimation or quantification of metals in a solution.

\section{CONCLUSION}

Copper and iron cause spectroscopic shifts of bugnay anthocyanins in acidic solutions through the formation of metal-anthocyanin complexes. Bugnay anthocyanins contain three pigments based from high performance liquid chromatography, one of which is cyanidin-3-0glucoside. The maximum absorbance of bugnay anthocyanins at $\mathrm{pH} 1.0$ and 4.5 were noted at $520 \mathrm{~nm}$ and $350 \mathrm{~nm}$, respectively. Copper causes significantly greater hypochromic shifts and hypsochromic shift towards $350 \mathrm{~nm}$ at $\mathrm{pH} 1.0$ compared to iron. Iron causes slightly greater hypochromic shift compared to copper at $\mathrm{pH} 4.5$. The concentration of copper showed significant positive moderate correlation with mean \% absorbance difference at $\mathrm{pH} 1.0$ and 4.5 while iron showed significant moderate correlation at 4.5 only. Highly acidic $\mathrm{pH}$ favors the formation of copper-anthocyanin complex while moderately acidic pH favors ironanthocyanin complex, suggesting different schemes of metal-anthocyanin complex formation. The results show that bugnay anthocyanins can serve as potential sensors of copper and iron in acidic aqueous solutions by using their spectroscopic shifts. However, the stability of the system needs to be improved.

\section{ACKNOWLEDGEMENT}

The authors would like to thank Dr. Evelyn Oda and Mr. Jenner Butlong for their assistance in SLU-NSRU.

\section{REFERENCES}

ACAR, O., OZVATAN, S. and ILIM, M. 2005. Determination of cadmium, copper, iron, manganese, lead and zinc in lichens and botanic samples by electrothermal and flame atomic absorption spectrometry. Turkish Journal of Chemistry 29, 335-344.

AHMED, MJ. And ROY, UK. A simple spectrophotometric method for the determination of iron (II) aqueous solutions. Turkish Journal of Chemistry 33,709-726. 
Detection of copper and iron in aqueous solutions using spectroscopic

AOAC OFFICIAL METHOD 2005.02. 2006. Total monomeric anthocyanin pigment content of fruit juices, beverages, natural colorants, and wines$p H$ differential method first action 2005. Journal of Association of Analytical Chemists International 88:1269.

AMELIA, F., AFNANI, G., MUSFIROH, A., FIKRIYANI, A., UCCHE, S., and MURRUKMIHADI, M. 2006. Extraction and stability test of anthocyanin from buni fruits (Antidesma Bunius $L$ ) as an alternative natural and safe food colorants. Journal of Food and Pharmacologic Sciences 1:49-53.

BROUILLARD, R., CHASSAING S., ISOREZ G., KUENY-STOTZ M., and FIGUEIREDO P. 2010. The visible flavonoids or anthocyanins: From research to applications. Recent Advances in Polyphenol Research 2:122.

CHENG, G.. and CRISOSTO, C. 1997. Iron-polyphenol complex formation and skin discoloration in peaches and nectarines. Journal of the American Society for Horticultural Science 122(1):95-99.

GEORGE, F., FIGUEIREDO, P., and BROUILLARD, R. 1999. Malvin Z-chalcone: An unexpected new open cavity for the ferric ion. Phytochemistry 50:1391-1394

JENSHIROOBHA, J., SARAVANAKUMAR, M., ARAVINDHAN, K., and SUGANYA DEVI, P. 2011. The effect of light, temperature, $p H$ on stability of anthocyanin pigments in Musa acuminata bract. Research in Plant Biology 1(5):5-12.

LAVIE, R. 1998. Iron and copper overload. Consumer Health 21(6).

LI, H., GUO, A., and WANG, H. 2008. Mechanisms of oxidative browning of wine. Food Chemistry 108:1-13.

KONCZAK, I. and ZHANG, W. 2004. Anthocyanins-More than nature's colours. Journal of Biomedicine and Biotechnology 5:239-240.

MONCADA, M., MOURA, S., MELO, J., ROQUE, A., LODEIRO, C., and PINA, F. 2003. Complexation of aluminum (III) by anthocyanins and synthetic flavylium salts; a source for blue and purple color. Inorganic Chemica Acta 356:51-61. 
MORTON, J. 1987. Fruits of Warm Climates. Creative Resource Systems, Inc.: 210-212.

OZER, A., and TUMEN, F. 2005. Cu (II) adsorption from aqueous solutions on sugar beet pulp carbon. The European Journal of Mineral Processing and Environmental Protection 5(1):26-34.

PATRUDU, T.B. and RAJU, K.V. 2011. Reductimetric determination of copper (II) with iron (II) in phosphoric acid medium and in presence of bromide ion. Research Journal of Chemical Sciences 1(3): 6-9.

PYYSALO, H. and KUUSI, T. 1973. The role of iron and tin in discoloration of berry and red beet juices. Zeitschrift für Lebensmittel Untersuchung und Forschung 53:224-233.

QIN, C., LI, Y., NIU, W., DING, Y., ZHANG, R. and SHAN, X. 2010. Analysis and Characterisation of Anthocyanins in Mulberry Fruit. Czech Journal of Food Sciences 28(2): 117-126.

REIN, M. 2005. Copigmentation reactions and color stability of berry anthocyanins. Academic Dissertation of University of Helsinki, Department of Applied Chemistry and Microbiology.

SARMA, A and SHARMA, R. 1999. Anthocyanin-DNA copigmentation: Mutual protection against oxidative damage. Phytochemistry 52:13131318.

SARMA, A., SREELAKSHMI, Y. and SHARMA, R. 1997. Antioxidant ability of anthocyanins against ascorbic acid oxidation. Phytochemistry 45(4):671-674.

WROLSTAD, R., DURST, R. and LEE, J. 2005. Tracking color and pigment changes in anthocyanin products. Trends in Food Science and Technology 16:423-428. 